\title{
XCI in preimplantation mouse and human embryos: first there is remodelling...
}

\author{
I. M. van den Berg • R. J. Galjaard · J. S. E. Laven • \\ J. H. van Doorninck
}

Received: 31 March 2011 / Accepted: 19 May 2011 / Published online: 7 June 2011

(C) The Author(s) 2011. This article is published with open access at Springerlink.com

\begin{abstract}
Female eutherians silence one of their X chromosomes to accomplish an equal dose of $\mathrm{X}$-linked gene expression compared with males. The mouse is the most widely used animal model in XCI research and has proven to be of great significance for understanding the complex mechanism of X-linked dosage compensation. Although the basic principles of XCI are similar in mouse and humans, differences exist in the timing of XCI initiation, the genetic elements involved in XCI regulation and the form of XCI in specific tissues. Therefore, the mouse has its limitations as a model to understand early human XCI and analysis of human tissues is required. In this review, we describe these differences with respect to initiation of XCI in human and mouse preimplantation embryos, the extraembryonic tissues and the in vitro model of the epiblast: the embryonic stem cells.
\end{abstract}

\section{Introduction}

This year, we celebrate the 50th anniversary of Mary Lyon's first publication on X chromosome inactivation. Her first study hypothesized about the basic principle of $\mathrm{X}$ chromosome inactivation (XCI) that would result in dosage compensation of $\mathrm{X}$-linked gene expression between

I. M. van den Berg · J. S. E. Laven · J. H. van Doorninck $(\bowtie)$

Department of Obstetrics and Gynecology,

Subdivision of Reproductive Medicine, Erasmus Medical Center, Rotterdam, The Netherlands

e-mail: j.vandoorninck@erasmusmc.nl

I. M. van den Berg · R. J. Galjaard · J. H. van Doorninck Department of Clinical Genetics, Erasmus Medical Center, Rotterdam, The Netherlands male and female mice. Brown et al. (1991) described a gene that was exclusively expressed from the inactive $\mathrm{X}$, the Xi-specific transcripts (Xist), and it was proposed to be involved in the process of XCI (reviewed in Plath et al. 2002). XCI has become a research field of its own, and many genes have been discovered to be involved in the process of sex-linked dosage compensation. The mechanism of XCI comprises different aspects of molecular biology, cell biology and epigenetics, and it combines many fields of not only basic research, but also translational science. Although the general outcome of the X-inactivation process is similar in somatic cells of mice and men, resulting in dosage compensation of $\mathrm{X}$-linked genes, there are important differences in the genes that take part in the initiation process of XCI, the extent of gene inactivation and how XCI occurs in different tissues. This review focuses on the similarities and the differences between mouse and human tissues with respect to the timing of XCI initiation at the earliest stages of development; namely (1) the preimplantation stage, (2) in extra-embryonic tissues and (3) in ES cells.

Brief introduction on some key players of human and mouse XCI

Excellent reviews exist that describe in detail the regulatory elements that are involved in $\mathrm{X}$-inactivation process (Barakat and Gribnau 2010; Chow and Heard 2009; Navarro and Avner 2009; Starmer and Magnuson 2009; Thorvaldsen et al. 2006). Most of these data are derived from mouse ES cell differentiation experiments and mutant mouse models. We briefly mention some of the genes here to describe their basic function and describe other genes in the ES cell section. Xist is the most important gene in XCI that codes for Xist, a non-coding RNA transcript which 
wraps itself around the future inactive $\mathrm{X}$ chromosome (Penny et al. 1996; Clemson et al. 1996). Human XIST shows sequence similarity to mouse Xist, but has large sequence divergence in the flanking regulatory regions (Chang and Brown 2010; Chureau et al. 2002). This may have consequences for the initiation and maintenance of XCI. The Tsix transcript is a key regulator of Xist in mouse tissues (Lee et al. 1999; Sado et al. 2001). It is expressed in opposite direction of Xist and thereby represses Xist expression. The balance between Xist and Tsix expression ensures that only one $\mathrm{X}$ chromosome is inactivated in females and none in males. The human TSIX region is not well conserved, the transcript is truncated and does not overlap the XIST promoter region and lacks other regulatory elements, such as DXPAS34, that are essential for murine Tsix function (Chureau et al. 2002; Cohen et al. 2007; Debrand et al. 1999; Migeon et al. 2002). Other murine genes that play a role in the XCI process in mouse ES cells, such as Rnf12, Jpx, Yy1, CTCF and Eed (Chao et al. 2002; Donohoe et al. 2007; Jonkers et al. 2009; Silva et al. 2003; Tian et al. 2010) are conserved in humans although differences exist between mice and humans in the flanking regions of some of the genes (Chang and Brown 2010; Chureau et al. 2002).

\section{XCI during preimplantation development, the first step}

$\mathrm{XCI}$ kinetics in mouse embryos

The first initiation of XCI starts at the 2-cell stage of preimplantation development. Mouse cleavage stage embryos have an imprinted form of XCI in which the inactivated chromosome is always the paternal $\mathrm{X}$ chromosome (Kay et al. 1993; Zuccotti et al. 2002). The second step comprises the reactivation of the paternal $\mathrm{X}$ in the inner cell mass (ICM) and the maintenance of imprinted XCI in the trophoectoderm (TE) and primitive endoderm (PrE) at day 4.5 (Mak et al. 2004; Okamoto et al. 2004; Silva et al. 2009; Sugawara et al. 1985). The third step is the initiation of random XCI in cells of the epiblast between days 5.5 and 6.3 (Rastan 1982; Takagi et al. 1982), which is recapitulated in in vitro ES cell differentiation experiments (Barakat and Gribnau 2010).

Most of our knowledge about XCI in preimplantation embryos comes from the analysis of mouse embryos that have imprinted XCI (reviewed in Okamoto and Heard 2006). Imprinted XCI is likely caused by opposite marks on the parental X chromosomes in oocytes and spermatozoa (Ariel et al. 1995; Norris et al. 1994; Tada et al. 2000; Zuccotti and Monk 1995). Both maternal and paternal imprints ensure the inactive status of $\mathrm{Xp}$ and the active status of Xm. It has been hypothesized that the paternal $\mathrm{X}$ chromosome enters the oocyte in a pre-inactivated state as a result from the chromatin remodelling and silencing process during spermatogenesis called meiotic sex chromosomes inactivation (MSCI) (Huynh and Lee 2003). However, several studies have shown that the paternal $\mathrm{X}$ is transcriptionally active at the 2-cell stage (Kalantry et al. 2009; Namekawa et al. 2010; Okamoto et al. 2004; Patrat et al. 2009). In addition, in a mouse model in which the murine Xist gene is translocated on an autosome, which is not subjected to MSCI or meiotic silencing of unsynapsed chromosomes (MSUC), Xist is still able to induce silencing of neighbouring genes and epigenetic remodelling of the ectopically Xist coated region (Okamoto et al. 2005). Thus, another feature may be responsible for paternal X-inactivation, for example, the presence of paternally specific histones or protamines. Furthermore, as will be discussed below, recent data suggest that initial silencing of X-linked genes may be Xist independent.

In a 2-cell stage mouse embryo, only a single pinpoint area of Xist RNA is present, but this pinpoint gradually expands to a full cloud at the 4-8 cell stage. At the 4-cell stage, the first signs of transcriptional repression of the $\mathrm{Xi}$ appear, including the exclusion of RNA polymerase II and the absence of transcription of Cot-1 repetitive elements (Huynh and Lee 2003; Okamoto et al. 2004). From the 8-cell stage onwards, epigenetic marks appear, such as hypoacetylation of $\mathrm{H} 3 \mathrm{~K} 9$ and $\mathrm{H} 3 \mathrm{~K} 4$ hypomethylation (Okamoto et al. 2004). Morula and blastocyst embryos show Eed/Ezh2 association on Xi (Erhardt et al. 2003; Okamoto et al. 2004), the incorporation of the histone variant macroH2 $\mathrm{A}$ and the accumulation of $\mathrm{H} 3 \mathrm{~K} 27$ trimethylation, although individual embryos are variable in the onset of these marks (Costanzi et al. 2000; Mak et al. 2004; Okamoto et al. 2004). This variability in chromatin modifications might be the consequence of the different levels of Xist RNA in the individual blastomeres (Hartshorn et al. 2003) and may be related to the fate of each cell in the 8-cell embryo. As the first cell differentiation takes place at the compaction stage, with the inner cells being predominantly future ICM cells and the outer cells future TE (reviewed in (Johnson and McConnell 2004; Zernicka-Goetz 2002), it is possible that this process of cell allocation and specification causes the reactivation of the paternal $\mathrm{X}$ in the ICM while the inactive state of $\mathrm{Xp}$ is maintained in the TE.

Although the female mouse preimplantation embryo displays almost all characteristics of XCI, some of the final features, such as DNA methylation of Xist on the Xa and Barr body formation, are not established (Huynh and Lee 2003). The lack of final modifications indicates that XCI during preimplantation development is not as complete as in somatic cells, thereby allowing the reactivation of the Xi in the ICM. 


\section{XCI kinetics in human embryos}

Studies in human preimplantation embryos have been hampered by difficulties in obtaining permission for research by ethics committees and in recruiting patients willing to donate their surplus embryos. Another difficulty is that surplus embryos can only be donated after the clinical phase of embryo transfer has been performed, and after the remaining good quality embryos are cryopreserved for future clinical use. Embryos of good quality at the earliest cleavage stages are thus even more difficult to obtain. Therefore, very few studies have used human embryos to examine dosage compensation by X-inactivation (Daniels et al. 1997; Okamoto et al. 2011; Ray et al. 1997; van den Berg et al. 2009).

Human embryos divide somewhat slower than mouse embryos; they consist of eight cells at day 3 and become morulas at day 4 and blastocysts at day 5 , while mouse embryos develop 1-2 days faster. In agreement with the slower development is the later activation of the human embryonic genome at the 4 to 8 -cell stage, while mice activate their genome at the 1 to 2-cell stage (Schultz 1993; Wells et al. 2005). This difference between mice and men is also reflected by the observation that human 8-cell stage embryos have a pinpoint expression of XIST, while mouse 8-cell stage embryos have already formed a full cloud of Xist expression by that time (Huynh and Lee 2003; Kalantry et al. 2009; Mak et al. 2004; Namekawa et al. 2010; Okamoto et al. 2004; van den Berg et al. 2009). Initial experiments with RT-PCR analysis showed that both female and male embryos expressed XIST (Daniels et al. 1997; Ray et al. 1997), which at the time led to the conclusion that XIST is not functional at these stages in human development. Subsequent experiments challenged these conclusions as single cell analysis of human embryos showed single XIST clouds defined as confined areas of XIST transcript accumulations in blastocysts (van den Berg et al. 2009). However, often, loose XIST transcripts throughout the nucleus are found which are not observed in human somatic cells (van den Berg et al. 2009 and unpublished observations). Unfortunately, it is not possible to identify the parental origin of the XIST cloud based on a single nucleotide polymorphisms in XIST as both the XIST cloud mRNA, as well as the loose XIST transcripts will be amplified with an RT-PCR (unpublished observations). Importantly, many hallmarks indicative of XCI, such as accumulation of H3K27me3 and macroH2a, hypoacetylation of $\mathrm{H} 3 \mathrm{~K} 9$, and the monoallelic silencing of a gene adjacent to XIST have been observed in single cell analysis of human female embryos (van den Berg et al. 2009), demonstrating that the process of XCI is initiated. A recent paper on XCI in rabbit and human embryos reported the presence of two XIST clouds in part of the human embryonic cells (Okamoto et al. 2011). We suspect that high XIST probe concentrations detect local accumulations of XIST transcripts that are not indicative of an inactivation process. It is clear that XCI in human embryos basically follows the same cascade of events observed in mouse embryos, although the timing differs (Fig. 1). Whether human embryos also show imprinted $\mathrm{Xi}$ at the preimplantation stage is not yet known, the predominantly single XIST pinpoints in human embryos may suggest that an imprinted mechanism of $\mathrm{Xi}$ takes place in human embryos.

Does Xist/XIST coating induces dosage compensation?

Whether the typical hallmarks of XCI lead to actual gene silencing and thus dosage compensation of X-linked coding genes is not yet known. As introduced above, initial silencing of X-linked genes during the first cleavage stages may occur independent of Xist expression and coating: a recent study shows that a majority of the X-linked genes have virtually wild-type expression rates in an Xist mutant background as no differences were found in the mono-allelic and bi-allelic expression rates (Kalantry et al. 2009). Interesting exceptions were the genes Rnf12 and Atrx. These genes were affected by the Xist deficiency and since they both play a role in the XCI process this may suggest the presence of feedback mechanisms. Rnf12 has recently been described as an activator of Xist in mouse ES cells (Barakat et al. 2011; Jonkers et al. 2009) and Atrx is essential for imprinted XCI in the murine placenta (Baumann and De La Fuente 2009; Garrick et al. 2006). These data suggest that initial silencing of certain regions of the $\mathrm{X}$ chromosome is Xist independent. Whether Xist independent silencing is in fact due to remaining marks of MSCI or protamines (Huynh and Lee 2003; Okamoto et al. 2004) is not yet known. This form of silencing may be reminiscent of a more ancient form of XCI, such as found in marsupials, which is also Xist independent (Chaumeil et al. 2011). At later stages, Xist is required to stabilize the imprinted XCI during further embryonic development (Kalantry et al. 2009). It has been postulated that the coating with Xist modified chromatin configuration creates a territory containing repetitive sequences into which genes can be recruited to be silenced (Chaumeil et al. 2006; Clemson et al. 2006). In embryos as well as in ES cells, the actual silencing of $\mathrm{X}$-linked genes and thus dosage compensation does not immediately follow the gradual coating by Xist (Huynh and Lee 2003; Kalantry et al. 2009; Lin et al. 2007; Mak et al. 2004; Namekawa et al. 2010). This indicates that the Xist expression and cloud formation alone is not sufficient for silencing (Namekawa et al. 2010). Instead, a gradual conversion of bi-allelic to mono-allelic expression of X-linked genes is observed. These highly dynamic 

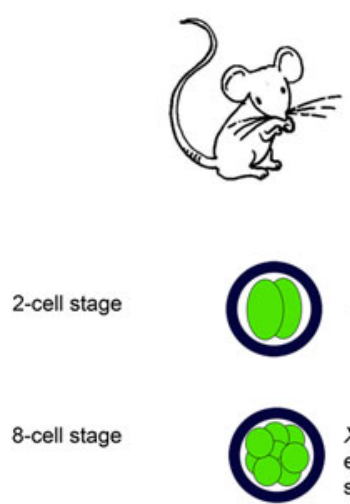

Xist pinpoint on Xp

Xist cloud

exlusion RNA pollI/COT-1 start chromatin remodelling (XCR)

blastocyst stage

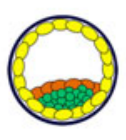

TE: maintenance XCR Xp $X$-linked gene silencing

PrE: maintenance XCR Xp $X$-linked gene silencing

ICM: reactivation $\mathrm{Xp}$ (loss of $\mathrm{XCR}$ )
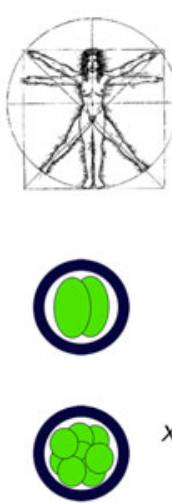

$?$

$X I S T$ pinpoint on $X(X p$ or $X m ?)$

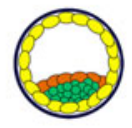

TE and PrE:

XIST cloud in $90 \%$ of cells

Exclusion COT-1

Start XCR in $30 \%$ of cells (H3K27me 3 ); remaining cells no epigenetic marks

ICM: unknown

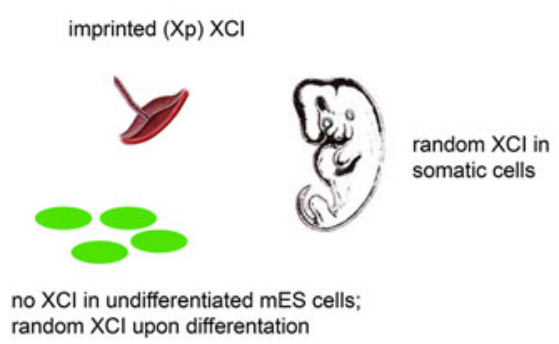

Fig. 1 Schematic overview of three different steps of XCI in mouse and man. Mouse: in the mouse 2-cell stage embryo, imprinted XCI begins with pinpoint Xist expression from the paternal X. At the 8-cell stage, the Xp chromosome is remodelled (XCR, see text for details) with COT-1 exclusion and epigenetic marks; this remodelled $\mathrm{X}$ chromosome becomes inactivated (XCI) at the blastocyst stage. Mouse blastocyst ICM cells reactivate the paternal X while the TE and PrE retain the imprinted form of XCI (see text for more detailed description). The imprinted form of XCI is maintained during development of the placenta, while the epiblast converts to a random XCI mechanism. Human: no data are available for single human 2-cell stage embryos regarding the level and location of XIST expression. At the 8-cell stage most cells have a single pinpoint of XIST expression but whether this

processes are reflected by the variability in silencing of genes along the $\mathrm{X}$ chromosome and the variability in silencing between individual blastomeres of single mouse and human embryos (Huynh and Lee 2003; Kalantry et al. 2009; Namekawa et al. 2010; Patrat et al. 2009; van den Berg et al. 2009). It can be postulated that this form of XCI, which starts with the remodelling of the future inactive $\mathrm{X}$ by chromatin modifications, but does not include Xist DNA methylation may allow for a more dynamic X-linked gene silencing at these early stages. observed XCl patterns in human placenta $50 \%$ skewed $\mathrm{XCl}$ of $\mathrm{Xp}$ $35 \%$ random $\mathrm{XCl}$ $15 \%$ skewed $\mathrm{XCl}$ of $\mathrm{Xm}$

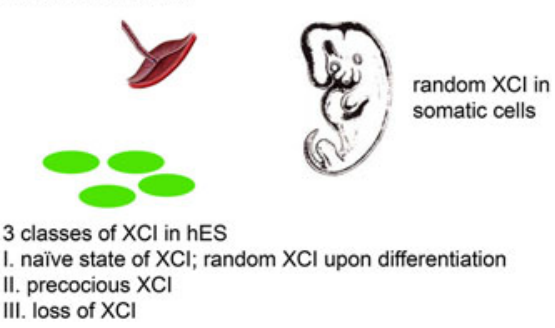

is an imprinted XCI is not yet known. Human blastocysts have a full cloud of XIST, COT-1 exclusion, epigenetic marks and mono-allelic expression of a gene adjacent to XIST in a portion of the cells, indicative of XCR and the initiation of XCI (van den Berg et al. 2009). Data on XCI in human placenta point towards a preferential silencing of the paternal allele, although random XCI patterns are often observed. The model hES cell lines to study random XCI are not as good in humans as they are in mice: whereas undifferentiated mouse ES cells have two active $\mathrm{X}$ chromosomes and upon differentiation randomly silence one $\mathrm{X}$ chromosome, undifferentiated human ES cells are extremely variable in XIST expression and so far three classes have been described (see text). ICM Inner cell mass, TE trophoectoderm, $\operatorname{PrE}$ primitive endoderm 
pattern of Xist and imprinted placental genes (Doherty et al. 2000; Mann et al. 2004; Market-Velker et al. 2010; Rivera et al. 2008). Culture conditions, such as glucose levels that have no impact on epiblast development, do affect TE differentiation (Leunda-Casi et al. 2001). These findings suggest that the extra-embryonic lineages may be different from the epiblast with respect to epigenetic regulation. This difference indicates that the manipulation of preimplantation embryos influences imprinted gene expression, and this might be the case for human embryos from assisted reproductive technology (ART) treatments as well. Several studies on children conceived with ART treatments have shown a slightly higher incidence in imprinting disorders, an altered sex ratio shifted towards males, altered birth weight and even skewed XCI (Chang et al. 2009; Dumoulin et al. 2010; Halliday et al. 2004; Helmerhorst et al. 2004; King et al. 2010). A number of other reasons may also explain the differences between ART outcome and the general population, such as the reason for infertility of the parents, the ovarian stimulation procedure, the high amount of multiple pregnancies and the extended time to pregnancy (Owen and Segars 2009). Although the long-term effects are subtle, influences of the in vitro environment must be considered when studying human preimplantation development.

\section{XCI in extra-embryonic tissues, the second step}

Upon differentiation into blastocysts, the inactivation of the paternal $\mathrm{X}$ is maintained in the mouse trophoectoderm and will remain silenced all throughout placenta development. The overexpression of X-linked genes due to a lack of dosage compensation is lethal, primarily due to placental defects (Hemberger 2002). Whether a mouse embryo can survive with an extra $\mathrm{X}$ chromosome depends on the parental origin of the $\mathrm{X}$ chromosomes. Having two maternal $\mathrm{X}$ chromosomes is lethal $(\mathrm{XmXmY})$, whereas a single $\mathrm{Xp}$ or two paternal $\mathrm{X}$ chromosomes can be tolerated and corrected (Burgoyne et al. 2002; Goto and Takagi 2000; Matsui et al. 2001). This distinction suggests that the paternal imprint is much easier to reverse than a maternal imprint. In humans, the difference in embryo lethality caused by the parental origin of the $\mathrm{X}$ chromosome aberration is less pronounced. Whether a missing $\mathrm{X}$ chromosome or extra $\mathrm{X}$ chromosomes are paternally or maternally derived does not seem to be of great influence as both $\mathrm{XmXmY}$ and $\mathrm{XmXpY}$ Klinefelter syndrome genotypes as well as triple $\mathrm{X}$ women (XmXmXp or XmXpXp) are viable. Also in Turner patients (either XpO or $\mathrm{XmO}$ ) the parental origin of the $\mathrm{X}$ chromosomes does not seem to influence the pregnancy outcome (Jacobs and Hassold 1995). However, up to $90 \%$ of the human embryos with a single $\mathrm{X}$ chromosome die in utero due to the many pseudoautosomal and other escape genes on the human X chromo- some that are normally not silenced and are thus required at double dosage (Carrel and Willard 2005). These data suggest that in human placental development, the parental origin is of less importance in dosage compensation.

\section{Maintenance of imprinting in mice}

How the mouse paternal $\mathrm{X}$ retains the inactive mark is still unclear, but knockout experiments have identified genes that are essential for maintenance of imprinted XCI in the mouse placenta, namely Eed and Tsix (Kalantry and Magnuson 2006; Kalantry et al. 2006; Lee et al. 1999; Luikenhuis et al. 2001; Wang et al. 2001). Tsix, the antisense transcript of Xist, represses Xist expression on the future active $\mathrm{X}$. Tsix thereby ensures that only one $\mathrm{X}$ is inactivated in random XCI and protects the maternal X from inactivation in the placenta. The parental origin of the mutated Tsix allele therefore has a strong effect on future mouse placenta development. While the inheritance of a maternal Tsix deletion results in embryonic lethality during post-implantation development around d9.5, inheritance of a paternal Tsix mutation has no effect in female embryos (Lee 2000; Sado et al. 2001). In humans, TSIX does not seem to play a role in the process of XCI, as the sequence is truncated compared with its murine counterpart and is, unexpectedly, transcribed from the same allele as XIST (Migeon et al. 2001, 2002). Thus, it is not likely that human $\mathrm{XCI}$ is regulated by TSIX expression, neither in the embryo nor in the extra-embryonic lineages.

The polycomb protein Eed has been of interest, as it is required to keep the paternal $\mathrm{X}$ chromosome inactive in the extra-embryonic tissue (Kalantry et al. 2006). Other signals that may be important for the maintenance of the imprinted state in trophoblast cells could be present in the blastocoel fluid, which has direct contact with both the trophoblast as well as the primitive endoderm cells, the two cell types that contain the imprinted XCI mark. A study on imprinted XCI that used mouse ES cell differentiation towards the extraembryonic lineages found that imprinted XCI was not initiated in this in vitro system. Subsequent cloning of the nucleus of this ES cell line into an oocyte resulted in aberrant random XCI in the trophoectoderm of the resulting blastocyst (Murakami et al. 2011). This study indicates that ICM cells lose the memory of the $\mathrm{X}$ imprint during the reactivation process and that $\mathrm{TE}$ cells can only maintain and actively secure the inactive Xp when they directly originate from the preimplantation embryo.

Do humans prefer to inactivate the paternal $\mathrm{X}$ chromosome during placenta development?

Many studies have analysed whether XCI is imprinted in human extra-embryonic tissues similar to mouse 
trophectoderm, but the results have been contradictory. Preferential imprinted XCI such as is found in mouse embryos describes a situation in which part of the cells show XCI and those always inactivate the paternal X, whereas the other cells do not show signs of XCI. On the other hand, a completely imprinted pattern describes the situation as found in the mouse trophectoderm in which all cells showing paternal XCI. Skewing on the other hand is defined as a bias of XCI towards the paternal or maternal allele, usually of 70-75\% instead of the normal 50:50 ratio. About half of the human placental tissues and isolated trophoblast and cytotrophoblast cells showed skewing towards the paternal X chromosome, but the remainder of the samples showed no skewing or skewing towards the maternal allele (Goto et al. 1997; Harrison 1989; Harrison and Warburton 1986; Looijenga et al. 1999; Migeon and Do 1978; Migeon et al. 1985; Moreira de Mello et al. 2010; Ropers et al. 1978; Willemsen et al. 2002; Zeng and Yankowitz 2003). No consistency exists between studies that investigated the same tissue or gene, and it is difficult to clarify the discrepancies, as studies with different outcomes used essentially the same methodology.

Two studies investigated XCI after in vitro differentiation of trophoectoderm from ES cells. In one study using human ES cells, it was suggested that imprinted XCI can be recapitulated upon differentiation towards the extra-embryonic lineages (Dhara and Benvenisty 2004). However, as the parental origin of the $\mathrm{X}$ chromosome was not determined, imprinted XCI of the paternal X in human TE cells is not yet conclusive. In addition, whether ES cell lines are an appropriate model to study in vitro trophoectoderm differentiation is questionable based on the observations from the recent publication discussed above: the initiation of imprinted XCI was not possible in vitro, but required in vivo differentiation (Murakami et al. 2011).

What is the underlying mechanism to explain the different observations from placental studies? If preferential silencing of the paternal allele occurs at the human blastocyst stage, perhaps implied by the prevalence of single pinpoints at the cleavage stage (van den Berg et al. 2009), it would explain the skewing of XCI towards the paternal allele that has mostly been found in human placental material (Goto et al. 1997; Harrison 1989; Migeon et al. 2005; Mohandas et al. 1989; Ropers et al. 1978). It could be hypothesized that during human placental development an initial preferential silencing of the paternal allele that is not as rigid and stable as in the mouse, allows for the reactivation of the paternal $\mathrm{X}$ followed by random XCI. Indeed, reactivation of the Xi has been observed in human placental cells of spontaneous abortion material (Migeon et al. 2005), and in somatic cells containing a transgene of Xist, XCI can also be reversed in vitro (Chow et al. 2007). Such mechanisms of reversible XCI could explain the variable results of independent studies on human extra-embryonic tissues. A slightly different explanation can be made from the observation that only a subset of the cells in human blastocysts carries the visible epigenetic mark of XCI (van den Berg et al. 2009). If these cells start with a paternal XCI, and the other cells convert to random $\mathrm{XCI}$ at a later time point, it will result in a mixture of skewed $\mathrm{XCI}$ and random XCI within the studied placentas. It is clear that the final choice of XCI in the placenta occurs fairly early, as large patches of placental villi demonstrate the same choice of XCI (Looijenga et al. 1999; Willemsen et al. 2002).

If, in contrast, there is no preferential imprinted XCI, but random XCI in human blastocysts, it is not easy to explain the predominance of the preferential silencing of the paternal $\mathrm{X}$ found in human placentas. Perhaps, the skewed patterns of XCI found at later stages of placental development could be attributable to a selective advantage, only favourable in the placenta, of paternally silenced X-linked genes (Hemberger 2002). Alternatively, the single gene analysis used in most placental X-inactivation studies may have inadvertently created a bias towards imprinted Xp results. If this is true the actual random $\mathrm{X}$-inactivation pattern may be better represented by the analysis of more genes along the X chromosome (Moreira de Mello et al. 2010).

\section{Initiation of random XCI in the epiblast and embryonic stem cells, the third step}

The third step of XCI takes place in the ICM cells of the blastocyst that will become epiblast cells. It follows the reactivation of the paternal $\mathrm{X}$ chromosome and results in random XCI in the epiblast (Mak et al. 2004; Okamoto et al. 2004). Mouse embryos at day 3.5 have already formed an ICM, but these cells still contain an inactive $\mathrm{X}$ as shown by Xist clouds. These cells show high levels of pluripotency proteins, such as OCT4, SOX2 and NANOG. In the mature blastocyst at day 4.5, only the ICM cells that are NANOG positive will reactivate the paternal X chromosome. The other ICM cells that are expressing GATA4/ GATA6 will maintain the silenced paternal $\mathrm{X}$ and differentiate into PrE. Thus, both the TE and PrE maintain the same imprinted form of XCI (Mak et al. 2004; Silva et al. 2009). At day 5.5-6, epiblast cells will initiate random XCI (Mak et al. 2004; Takagi et al. 1982), and this process can be recapitulated in ES cells. Therefore, one of the main characteristics of an undifferentiated state of female ES cell lines is the active state of both $\mathrm{X}$ chromosomes (Barakat and Gribnau 2010; Silva et al. 2008).

Mouse models of random XCI initiation

Because ES cell lines were first derived from mice, initiation of random XCI has been extensively studied in this in 
vitro model. Upon differentiation, both $\mathrm{X}$ chromosomes begin to express Xist at a low level, but only one X chromosome will upregulate Xist expression. At day 7 of ES cell differentiation, $80 \%$ of the cells will have formed a single Xist cloud (Monkhorst et al. 2008). The random choice of the $\mathrm{X}$ chromosome that becomes inactivated has been a subject of study ever since Mary Lyon's first paper and different theories have been postulated as to how this random inactivation is regulated (Starmer and Magnuson 2009). Although studies using mouse ES cells have provided key insights in the process, important questions still remain, and novel genes are continuously being discovered (reviewed in Barakat et al. 2010; Chaumeil et al. 2002; Navarro and Avner 2009, 2010).

Xist regulatory sequences contain binding sites for NANOG, OCT4 and SOX2 (Navarro et al. 2008). Furthermore, downregulation of Nanog expression results in upregulation of Xist, independent of Tsix (Navarro et al. 2010). Several candidate genes for Xist regulation have been described in mouse ES cells, for example, Rnf12 and Jpx. Both are X-linked genes and located distal from Xist. Rnf12 is implied to function as an activator of Xist in both imprinted and random XCI although observations and conclusions do not completely agree (Barakat et al. 2011; Jonkers et al. 2009; Shin et al. 2010). Homozygous mutant Rnf12 female ES cells do not upregulate Xist expression upon differentiation and only sporadic XCI occurs. However, in heterozygous mutant female ES cells, that have the same protein level as male ES cells, XCI occurs in a delayed fashion upon differentiation indicating that there are more Xistactivating factors involved that either operate at different time points or in different doses. Ectopic expression of additional copies of human RNF12 in mES cells has the same effect indicating that the function of RNF12 is likely conserved (Barakat et al. 2011; Jonkers et al. 2009); however, experiments in hES cells are needed to support this.

The Jpx gene is a likely candidate co-activator of Xist. Deletion of Jpx has no effect in male ES cells, heterozygous female mutant cells, however, showed impaired EB formation after differentiation and whereas wild-type female ES cells contained a single cloud of Xist in $75 \%$ of the cells at day 8 , heterozygous $\Delta \mathrm{Jpx}$ mutant cells only had a single cloud of Xist in $6.35 \%$ of the cells. The effect of $\Delta \mathrm{Jpx} /+$ was rescued by placing it into a Tsix mutant background indicating the opposite action of both genes (Tian et al. 2010). Although mostly conserved, human JPX differs from murine Jpx as the distance between the JPX CpG island and the first exon 9 is times larger and no sequence conservation of this region has been found (Chang and Brown 2010). More research is needed to find out if human XCI is under the same genetic regulation as mouse XCI in ES cell differentiation.

As has been mentioned before, TSIX structure and function are not conserved in humans (Chureau et al. 2002;
Cohen et al. 2007; Migeon et al. 2002), therefore, other factors are expected to negatively regulate XIST expression from the future active $X$. Candidate genes for this function are the members of the polycomb repressive complex 2 (PRC2) namely Eed, EZH2 and Suz12 as they are responsible for the recruitment of repressive histone modifications, such as H3K9 and H3K27 methylation (Silva et al. 2003). Especially Eed has been of interest as it is needed to keep the paternal $\mathrm{X}$ chromosome inactive in the extra-embryonic tissue (Kalantry et al. 2006; Wang et al. 2001) and lack of Eed in the absence of Tsix results in elevated levels of Xist in differentiated male ES cells (Shibata et al. 2008). This resulted in partial XCI and retarded outgrowth of embryonic bodies (EB). Even at the undifferentiated state higher expression levels in the double mutant ES cells were found. However, this aberrant expression of Xist was rescued by ectopic expression of Eed. Thus, either Eed or Tsix is sufficient to repress Xist during random XCI. As humans lack a functional TSIX, EED might be the negative regulator of Xist in human cells. Indeed, PRC2 expression has been found in human preimplantation embryos at the 4-cell stage (Hinkins et al. 2005). However, functional data on human PRC2 proteins in human preimplantation embryos and hES cells are lacking.

The specific epigenetic hallmarks that are found on the inactive $X$ in somatic cells (Chadwick and Willard 2003) which are used to prove the initiation of XCI in preimplantation embryos are thought to silence the transcription machinery by recruiting specific silencing factors and forming a heterochromatic region. Candidate genes for recruiting modifying complexes or incorporating histone modifications on the $\mathrm{Xi}$ are the genes CTCF, YY1 and members of the polycomb repressive complexes 1 and 2 (PRC1 and PRC2) which are known to function as histone modifiers (Hernandez-Munoz et al. 2005; Schoeftner et al. 2006). CTCF and YY1 affect Xist expression (Donohoe et al. 2007) by changing the epigenetic status of the promoter. The human XIST promoter contains a much smaller CTCF binding site as compared to the mouse Xist promoter. It is however still functional as a single nucleotide polymorphism (SNP) in this site can cause skewing of XCI (Pugacheva et al. 2005). Nevertheless, the effect of the polymorphism is moderate as males do not seem to be affected.

The current challenge is to embed all these proteins in a complete network that integrates time and space during epiblast and extra-embryonic development.

Why we know little about human ES cells

The regulation of TE and ICM differentiation in human blastocysts has not been well studied. This lack of research is surprising, because many hES cell lines have been characterised 
without the knowledge of the ground state of pluripotency in human ICM cells. For instance, it is unknown whether human ICM have the same expression profile of pluripotency genes and epigenetic make-up as mouse ICM cells. This lack of knowledge hampers the proper evaluation of the quality of existing human ES cell lines. A reason for this lack of knowledge may be the ethical issues and scarcity of surplus human embryos. More research on human ICM cells would contribute to establishing high quality hES and iPS cell lines both for basic research on XCI kinetics as well as regenerative medicine.

\section{Human models of random XCI initiation}

How the process of XCI initiation is regulated in human ES cells is much less understood, and how it is regulated in vivo is not possible to investigate. A number of studies have investigated the XCI state in different hES cell lines and it is clear that human ES cells are quite different in several aspects, including XCI, from mouse ES cells (Dhara and Benvenisty 2004; Dvash et al. 2010; Enver et al. 2005; Hall et al. 2008; Hoffman et al. 2005; Liu and Sun 2009; Shen et al. 2008; Silva et al. 2008; Tanasijevic et al. 2009). Human ES cell lines that are characterised as being undifferentiated based on morphologic features and the presence of pluripotency markers show a highly variable pattern of XCI. In general, three patterns of XCI have been observed in hES cell lines: (a) cell lines that showed no signs of XCI, but initiate XCI upon differentiation, (b) cell lines in which $20-80 \%$ of the cells have an XIST cloud or an epigenetic hallmark of XCI, such as $\mathrm{H} 3 \mathrm{~K} 27 \mathrm{me} 3$, macroH2A or H4K20me1, indicative of precocious XCI at d0 of differentiation and (c) cell lines without XIST either at $\mathrm{d} 0$ or upon differentiation (Hall et al. 2008). It has been postulated that the long-term culture and frequent passaging of the cell lines may introduce artefacts, such as loss of XIST and expression of the $\mathrm{Xi}$. This may be possible but precocious XCI is also already present in very early passages of some newly established cell lines (Dvash et al. 2010) and has further been observed in human iPS cells (Tchieu et al. 2010). Further, it is possible that human ES cells are derived from ICM cells that have not yet reactivated their Xi and that the observed XCI in the hES cell lines is in fact a remnant from the XCI at the preimplantation stage. Indeed, some hES cell lines have a non-random precocious XCI and reversal to a random pattern of Xlinked gene silencing has been observed (Dvash et al. 2010; Shen et al. 2008). It has also been proposed that the hES cell lines currently available are actually epiblast stem cells lines and thus one step further differentiated than cells from the ICM (Brons et al. 2007; Lovell-Badge 2007; Tesar et al. 2007). Lastly, it has been proposed that specific culture conditions during the derivation process may influ- ence the pluripotency state of human ES cells (Hanna et al. 2010), and these conditions may also have consequences for XCI regulation. Indeed, a recent study showed that human ES cells, when cultured under physiological low $\mathrm{O}_{2}$-tension, reactivate the $\mathrm{Xi}$ and more closely resemble mES cells than cells that were cultured under atmospheric conditions (Lengner et al. 2010). Still, this finding indicates that the process of XCI is differently regulated in human compared with mouse ES cells. The reason for this difference in sensitivity between human and mouse may originate in the genetic elements that are involved in XCI (Chang and Brown 2010; Chureau et al. 2002). Importantly, only a few mouse strains allow the derivation of pluripotent ES cell lines using conventional culture conditions (Gardner and Brook 1997), indicating that genetic variations such as SNPs and CNVs are of influence on the successful isolation of undifferentiated ES cell lines. As human embryos are far more genetically diverse than most commonly used mouse strains, the derivation of human ES and iPS cell lines may require embryo tailored culture conditions. Recent progression in ES cell derivation using small molecule inhibitors allow the derivation of ES cells from virtual all mouse strains (Blair et al. 2011) and possibly from humans as well.

\section{Discussion}

In the past 50 years, much research has been carried out to unravel the phenomenon of mammalian X-linked dosage compensation. Although we now understand the basic principles of $\mathrm{X}$ chromosome inactivation, it is still remarkable that two chromosomes that are genetically the same are epigenetically complete opposites. Monotremes and marsupials have solved the dosage compensation problem by always inactivating the paternal allele. This imprinted form of XCI is also present in the preimplantation embryo and extra-embryonic tissues of the mouse. Whether human preimplantation embryos and early placenta also prefer to inactive the paternal $\mathrm{X}$ has yet to be determined. Human cleavage stage embryos have $26.5 \%$ cells with double staining for XIST signals (van den Berg et al. 2009) that may be reminiscent of a counting and choice mechanism such as found in differentiating ES cells. However, the predominant single XIST pinpoints in $68 \%$ of the cells at this stage (van den Berg et al. 2009) more resemble the single Xist pinpoints in imprinted XCI in mouse embryos. Up till now, the placenta data are variable, but most evidence points towards an initial preference for a paternal Xi (Goto et al. 1997; Harrison 1989; Harrison and Warburton 1986; Looijenga et al. 1999; Migeon and Do 1978; Migeon et al. 1985; Moreira de Mello et al. 2010; Ropers et al. 1978; Willemsen et al. 2002; Zeng and Yankowitz 2003). As mentioned 
before, two pathways could explain the observed preferential silencing of the paternal $X$ in human placentas. Either a paternal imprint in the trophectoderm is diluted or reversed with random XCI during further development. However, an argument against an imprinted form of XCI is the equal birth rate of children with an extra maternal or paternal $\mathrm{X}$ chromosomes such as in Klinefelter (XXY) syndrome (Jacobs et al. 1988; Lorda-Sanchez et al. 1992) or the relatively healthy status of triple X females (XXX). There are no indications that embryos with extra maternal chromosomes (XmXmXp or XmXmY) have more in utero demise than embryos with an extra paternal $\mathrm{X}$ chromosome (XmXpXp or XmXpY) (Jacobs and Hassold 1995). Thus, in contrast to female mice where an extra maternal $\mathrm{X}$ is lethal for placenta development, the equal birth rates of children with an extra Xm or an extra $\mathrm{Xp}$ in humans suggests that the parental origin of the sex chromosome aberration is of less importance for embryonic survival. How can these clinical data pointing at random XCI correspond to the molecular data from preimplantation embryos and placental tissues that more resemble an imprinted XCI mechanism?

\section{Difference between X-linked remodelling and X-linked inactivation?}

Although various hallmarks of somatic XCI are found in the mouse preimplantation embryo, a disturbance of the process, such as a mutation in an XCI essential gene, does not immediately interfere with mouse development at the preimplantation stage; rather, such a disturbance only affects post-implantation development from $\mathrm{d} 6$ onwards leading to death at day 7.5-9. In embryos that carry a deletion of the paternal Xist gene or parthenogenetic embryos, which do not have a paternal genome, imprinted XCI is recued by maternal Xist expression in a subset of the cells. However, these embryos arrest during post-implantation most likely due to poor development of the extra-embryonic tissues (Lee 2000; Marahrens et al. 1997; Nesterova et al. 2001). This late death suggests that dosage compensation is not immediately necessary, and that there is a window to establish silencing.

Both mouse embryos as well as ES cell differentiation experiments have shown that hallmarks for $\mathrm{X}$-inactivation, such as the presence of clouds of Xist, exclusion of RNA pol II and several epigenetic remodelling characteristics does not necessarily indicate that the $\mathrm{X}$ chromosome is completely silenced (Kalantry et al. 2009; Namekawa et al. 2010; Patrat et al. 2009). Thus, Xist clouds and epigenetic remodelling in preimplantation embryos may suggest the initiation of a dosage compensation mechanism, but do not tell us to what extent the $\mathrm{X}$ chromosome is actually silenced at this stage. This epigenetic $\mathrm{X}$ chromosome remodelling (XCR) modifies the $\mathrm{X}$ chromosome into a repressive state that allows future XCI. XCR only creates the possibility for individual genes recruited to be silenced (Chaumeil et al. 2006; Clemson et al. 2006) rather than that it automatically leads to complete dosage compensation. It is thus possible that only in the extra-embryonic trophoectoderm the chromosome wide XCI with definite silencing is completed.

\section{Necessity of dosage compensation}

It may be that early remodelling of the $\mathrm{Xp}$ in mouse embryos, 3 days before implantation, is not essential for the early embryo itself, but prepares for immediate dosage compensation in the extra-embryonic tissues from the moment of implantation onwards. If dosage compensation is only necessary from this point onwards, the late lethality of mouse embryos that carry XCI knockout genes can be better understood. Thus, also in human embryos, the initiation of XCI in blastocysts may not indicate actual inactivation and a widespread dosage compensation mechanism, but only remodelling of the $\mathrm{X}$ chromosome. So far, only one gene shows mono-allelic expression in human blastocysts (van den Berg et al. 2009). A possible effect of the process of XCI in human preimplantation embryos may be the observed retarded growth of female blastocysts (Alfarawati et al. 2011; Chang et al. 2009); however, it is not known whether this is linked to $\mathrm{X}$-inactivation, imprinted genes on the $\mathrm{X}$ or an effect of the $\mathrm{Y}$ chromosome.

The necessity for immediate dosage compensation in the placenta could be more acute in mice than in humans. Two reasons may account for the divergence between mouse and men: first, the mouse has a large amount of X-linked placental genes that are essential for proper placental development (Hemberger 2002). Second, as human embryos develop along a different, slower time line than mouse embryos, the lack of dosage compensation may be tolerated for a longer period. However, actual data on this are not known and many embryos may be lost as most studies on human birth rates do not include the possible death of an embryo before a recognised pregnancy (Macklon et al. 2002). Whether failures in $X$-inactivation play a role in these first trimester deaths is not known.

As science progresses to unravel the mechanism of mammalian dosage compensation, it has become clear that with the in-depth knowledge gained of this process in the mouse, the challenge remains to extrapolate these findings to the human. The differences in preimplantation and postimplantation development, in the genetic elements of the $\mathrm{XIC}$ and the heterogeneity amongst humans require that human XCI should be studied from its own point of view. With this review on the three steps of XCI initiation, we hope to provide novel insight regarding the differences that exist between humans and mice. 
Open Access This article is distributed under the terms of the Creative Commons Attribution Noncommercial License which permits any noncommercial use, distribution, and reproduction in any medium, provided the original author(s) and source are credited.

\section{References}

Alfarawati S, Fragouli E, Colls P, Stevens J, Gutierrez-Mateo C, Schoolcraft WB, Katz-Jaffe MG, Wells D (2011) The relationship between blastocyst morphology, chromosomal abnormality, and embryo gender. Fertil Steril 95:520-524

Ariel M, Robinson E, McCarrey JR, Cedar H (1995) Gamete-specific methylation correlates with imprinting of the murine Xist gene. Nat Genet 9:312-315

Barakat TS, Gribnau J (2010) X chromosome inactivation and embryonic stem cells. Adv Exp Med Biol 695:132-154

Barakat TS, Jonkers I, Monkhorst K, Gribnau J (2010) X-changing information on X inactivation. Exp Cell Res 316:679-687

Barakat TS, Gunhanlar N, Pardo CG, Achame EM, Ghazvini M, Boers R, Kenter A, Rentmeester E, Grootegoed JA, Gribnau J (2011) RNF12 activates Xist and is essential for X chromosome inactivation. PLoS Genet 7:e1002001

Baumann C, de La Fuente R (2009) ATRX marks the inactive X chromosome $(\mathrm{Xi})$ in somatic cells and during imprinted $\mathrm{X}$ chromosome inactivation in trophoblast stem cells. Chromosoma 118:209-222

Blair K, Wray J, Smith A (2011) The liberation of embryonic stem cells. PLoS Genet 7:e1002019

Brons IG, Smithers LE, Trotter MW, Rugg-Gunn P, Sun B, Chuva de Sousa Lopes SM, Howlett SK, Clarkson A, Ahrlund-Richter L, Pedersen RA, Vallier L (2007) Derivation of pluripotent epiblast stem cells from mammalian embryos. Nature 448:191-195

Brown CJ, Ballabio A, Rupert JL, Lafreniere RG, Grompe M, Tonlorenzi R, Willard HF (1991) A gene from the region of the human $\mathrm{X}$ inactivation centre is expressed exclusively from the inactive X chromosome. Nature 349:38-44

Burgoyne PS, Ojarikre OA, Turner JM (2002) Evidence that postnatal growth retardation in XO mice is due to haploinsufficiency for a non-PAR X gene. Cytogenet Genome Res 99:252-256

Carrel L, Willard HF (2005) X-inactivation profile reveals extensive variability in $\mathrm{X}$-linked gene expression in females. Nature 434:400-404

Chadwick BP, Willard HF (2003) Chromatin of the Barr body: histone and non-histone proteins associated with or excluded from the inactive X chromosome. Hum Mol Genet 12:2167-2178

Chang SC, Brown CJ (2010) Identification of regulatory elements flanking human XIST reveals species differences. BMC Mol Biol 11:20

Chang HJ, Lee JR, Jee BC, Suh CS, Kim SH (2009) Impact of blastocyst transfer on offspring sex ratio and the monozygotic twinning rate: a systematic review and meta-analysis. Fertil Steril 91:2381-2390

Chao W, Huynh KD, Spencer RJ, Davidow LS, Lee JT (2002) CTCF, a candidate trans-acting factor for $\mathrm{X}$-inactivation choice. Science 295:345-347

Chaumeil J, Okamoto I, Guggiari M, Heard E (2002) Integrated kinetics of $\mathrm{X}$ chromosome inactivation in differentiating embryonic stem cells. Cytogenet Genome Res 99:75-84

Chaumeil J, Le Baccon P, Wutz A, Heard E (2006) A novel role for Xist RNA in the formation of a repressive nuclear compartment into which genes are recruited when silenced. Genes Dev 20:2223-2237

Chaumeil J, Waters PD, Koina E, Gilbert C, Robinson TJ, Marshall Graves JA (2011) Evolution from XIST-independent to XISTcontrolled X-chromosome inactivation: epigenetic modifications in distantly related mammals. PLoS One 6:e19040
Chow J, Heard E (2009) X inactivation and the complexities of silencing a sex chromosome. Curr Opin Cell Biol 21:359-366

Chow JC, Hall LL, Baldry SE, Thorogood NP, Lawrence JB, Brown CJ (2007) Inducible XIST-dependent X-chromosome inactivation in human somatic cells is reversible. Proc Natl Acad Sci USA 104:10104-10109

Chureau C, Prissette M, Bourdet A, Barbe V, Cattolico L, Jones L, Eggen A, Avner P, Duret L (2002) Comparative sequence analysis of the $\mathrm{X}$-inactivation center region in mouse, human, and bovine. Genome Res 12:894-908

Clemson CM, McNeil JA, Willard HF, Lawrence JB (1996) XIST RNA paints the inactive $\mathrm{X}$ chromosome at interphase: evidence for a novel RNA involved in nuclear/chromosome structure. J Cell Biol 132:259-275

Clemson CM, Hall LL, Byron M, McNeil J, Lawrence JB (2006) The $\mathrm{X}$ chromosome is organized into a gene-rich outer rim and an internal core containing silenced nongenic sequences. Proc Natl Acad Sci USA 103:7688-7693

Cohen DE, Davidow LS, Erwin JA, Xu N, Warshawsky D, Lee JT (2007) The DXPas34 repeat regulates random and imprinted X inactivation. Dev Cell 12:57-71

Costanzi C, Stein P, Worrad DM, Schultz RM, Pehrson JR (2000) Histone macroH2 $\mathrm{A} 1$ is concentrated in the inactive $\mathrm{X}$ chromosome of female preimplantation mouse embryos. Development 127:2283-2289

Daniels R, Zuccotti M, Kinis T, Serhal P, Monk M (1997) XIST expression in human oocytes and preimplantation embryos. Am J Hum Genet 61:33-39

Debrand E, Chureau C, Arnaud D, Avner P, Heard E (1999) Functional analysis of the DXPas34 locus, a 3' regulator of Xist expression. Mol Cell Biol 19:8513-8525

Dhara SK, Benvenisty N (2004) Gene trap as a tool for genome annotation and analysis of $\mathrm{X}$ chromosome inactivation in human embryonic stem cells. Nucleic Acids Res 32:3995-4002

Doherty AS, Mann MRW, Tremblay KD, Bartolomei MS, Schultz RM (2000) Differential effects of culture on imprinted H19 expression in the preimplantation mouse embryo. Biol Reprod 62:1526-1535

Donohoe ME, Zhang LF, Xu N, Shi Y, Lee JT (2007) Identification of a Ctcf cofactor, Yy1, for the $\mathrm{X}$ chromosome binary switch. Mol Cell 25:43-56

Dumoulin JC, Land JA, Van Montfoort AP, Nelissen EC, Coonen E, Derhaag JG, Schreurs IL, Dunselman GA, Kester AD, Geraedts JP, Evers JL (2010) Effect of in vitro culture of human embryos on birthweight of newborns. Hum Reprod 25:605-612

Dvash T, Lavon N, Fan G (2010) Variations of X chromosome inactivation occur in early passages of female human embryonic stem cells. PLoS One 5:e11330

Enver T, Soneji S, Joshi C, Brown J, Iborra F, Orntoft T, Thykjaer T, Maltby E, Smith K, Abu Dawud R, Jones M, Matin M, Gokhale P, Draper J, Andrews PW (2005) Cellular differentiation hierarchies in normal and culture-adapted human embryonic stem cells. Hum Mol Genet 14:3129-3140

Erhardt S, Su I-h, Schneider R, Barton S, Bannister AJ, Perez-Burgos L, Jenuwein T, Kouzarides T, Tarakhovsky A, Surani MA (2003) Consequences of the depletion of zygotic and embryonic enhancer of zeste 2 during preimplantation mouse development. Development 130:4235-4248

Gardner RL, Brook FA (1997) Reflections on the biology of embryonic stem (ES) cells. Int J Dev Biol 41:235-243

Garrick D, Sharpe JA, Arkell R, Dobbie L, Smith AJ, Wood WG, Higgs DR, Gibbons RJ (2006) Loss of Atrx affects trophoblast development and the pattern of X-inactivation in extraembryonic tissues. PLoS Genet 2:e58

Goto Y, Takagi N (2000) Maternally inherited X chromosome is not inactivated in mouse blastocysts due to parental imprinting. Chromosome Res 8:101-109 
Goto T, Wright E, Monk M (1997) Paternal X-chromosome inactivation in human trophoblastic cells. Mol Hum Reprod 3:77-80

Hall LL, Byron M, Butler J, Becker KA, Nelson A, Amit M, ItskovitzEldor J, Stein J, Stein G, Ware C, Lawrence JB (2008) X-inactivation reveals epigenetic anomalies in most hESC but identifies sublines that initiate as expected. J Cell Physiol 216:445-452

Halliday J, Oke K, Breheny S, Algar E, JA D (2004) Beckwith-Wiedemann syndrome and IVF: a case-control study. Am J Hum Genet 75:526-528

Hanna J, Cheng AW, Saha K, Kim J, Lengner CJ, Soldner F, Cassady JP, Muffat J, Carey BW, Jaenisch R (2010) Human embryonic stem cells with biological and epigenetic characteristics similar to those of mouse ESCs. Proc Natl Acad Sci USA 107:9222-9227

Harrison KB (1989) X-chromosome inactivation in the human cytotrophoblast. Cytogenet Cell Genet 52:37-41

Harrison KB, Warburton D (1986) Preferential X-chromosome activity in human female placental tissues. Cytogenet Cell Genet 41:163-168

Hartshorn C, Rice JE, Wangh LJ (2003) Differential pattern of Xist RNA accumulation in single blastomeres isolated from 8-cell stage mouse embryos following laser zona drilling. Mol Reprod Dev 64:41-51

Helmerhorst FM, Perquin DA, Donker D, Keirse MJ (2004) Perinatal outcome of singletons and twins after assisted conception: a systematic review of controlled studies. BMJ 328:261

Hemberger M (2002) The role of the X chromosome in mammalian extra embryonic development. Cytogenet Genome Res 99:210-217

Hernandez-Munoz I, Lund AH, van der Stoop P, Boutsma E, Muijrers I, Verhoeven E, Nusinow DA, Panning B, Marahrens Y, van Lohuizen M (2005) Stable X chromosome inactivation involves the PRC1 Polycomb complex and requires histone MACROH2A1 and the CULLIN3/SPOP ubiquitin E3 ligase. Proc Natl Acad Sci USA 102:7635-7640

Hinkins M, Huntriss J, Miller D, Picton HM (2005) Expression of Polycomb-group genes in human ovarian follicles, oocytes and preimplantation embryos. Reproduction 130:883-888

Hoffman LM, Hall L, Batten JL, Young H, Pardasani D, Baetge EE, Lawrence J, Carpenter MK (2005) X-inactivation status varies in human embryonic stem cell lines. Stem Cells 23:1468-1478

Huynh KD, Lee JT (2003) Inheritance of a pre-inactivated paternal X chromosome in early mouse embryos. Nature $426: 857-862$

Jacobs PA, Hassold TJ (1995) The origin of numerical chromosome abnormalities. Adv Genet 33:101-133

Jacobs PA, Hassold TJ, Whittington E, Butler G, Collyer S, Keston M, Lee M (1988) Klinefelter's syndrome: an analysis of the origin of the additional sex chromosome using molecular probes. Ann Hum Genet 52:93-109

Johnson MH, McConnell JML (2004) Lineage allocation and cell polarity during mouse embryogenesis. Semin Cell Develop Biol 15:583-597

Jonkers I, Barakat TS, Achame EM, Monkhorst K, Kenter A, Rentmeester E, Grosveld F, Grootegoed JA, Gribnau J (2009) RNF12 is an $\mathrm{X}$-Encoded dose-dependent activator of $\mathrm{X}$ chromosome inactivation. Cell 139:999-1011

Kalantry S, Magnuson T (2006) The Polycomb group protein EED is dispensable for the initiation of random $\mathrm{X}$-chromosome inactivation. PLoS Genet 2:e66

Kalantry S, Mills KC, Yee D, Otte AP, Panning B, Magnuson T (2006) The Polycomb group protein Eed protects the inactive X-chromosome from differentiation-induced reactivation. Nat Cell Biol $8: 195-202$

Kalantry S, Purushothaman S, Bowen RB, Starmer J, Magnuson T (2009) Evidence of Xist RNA-independent initiation of mouse imprinted X-chromosome inactivation. Nature 460:647-651

Kay GF, Penny GD, Patel D, Ashworth A, Brockdorff N, Rastan S (1993) Expression of Xist during mouse development suggests a role in the initiation of X chromosome inactivation. Cell 72:171-182
King JL, Yang B, Sparks AE, Mains LM, Murray JC, Van Voorhis BJ (2010) Skewed X inactivation and IVF-conceived infants. Reprod Biomed Online 20:660-663

Lee JT (2000) Disruption of imprinted X inactivation by parent-of-origin effects at Tsix. Cell 103:17-27

Lee JT, Davidow LS, Warshawsky D (1999) Tsix, a gene antisense to Xist at the X-inactivation centre. Nat Genet 21:400-404

Lengner CJ, Gimelbrant AA, Erwin JA, Cheng AW, Guenther MG, Welstead GG, Alagappan R, Frampton GM, Xu P, Muffat J, Santagata S, Powers D, Barrett CB, Young RA, Lee JT, Jaenisch R, Mitalipova M (2010) Derivation of pre-X inactivation human embryonic stem cells under physiological oxygen concentrations. Cell 141:872-883

Leunda-Casi A, de Hertogh R, Pampfer S (2001) Control of trophectoderm differentiation by inner cell mass-derived fibroblast growth factor- 4 in mouse blastocysts and corrective effect of FGF-4 on high glucose-induced trophoblast disruption. Mol Reprod Dev 60:38-46

Lin H, Gupta V, Vermilyea MD, Falciani F, Lee JT, O’Neill LP, Turner BM (2007) Dosage compensation in the mouse balances upregulation and silencing of X-linked genes. PLoS Biol 5:e326

Liu W, Sun X (2009) Skewed X chromosome inactivation in diploid and triploid female human embryonic stem cells. Hum Reprod 24:1834-1843

Looijenga LH, Gillis AJ, Verkerk AJ, van Putten WL, Oosterhuis JW (1999) Heterogeneous $\mathrm{X}$ inactivation in trophoblastic cells of human full-term female placentas. Am J Hum Genet 64:1445-1452

Lorda-Sanchez I, Binkert F, Maechler M, Robinson WP, Schinzel AA (1992) Reduced recombination and paternal age effect in Klinefelter syndrome. Hum Genet 89:524-530

Lovell-Badge R (2007) Many ways to pluripotency. Nat Biotechnol 25:1114-1116

Luikenhuis S, Wutz A, Jaenisch R (2001) Antisense transcription through the Xist locus mediates Tsix function in embryonic stem cells. Mol Cell Biol 21:8512-8520

Macklon NS, Geraedts JP, Fauser BC (2002) Conception to ongoing pregnancy: the 'black box' of early pregnancy loss. Hum Reprod Update 8:333-343

Mak W, Nesterova TB, de Napoles M, Appanah R, Yamanaka S, Otte AP, Brockdorff N (2004) Reactivation of the paternal X chromosome in early mouse embryos. Science 303:666-669

Mann MRW, Lee SS, Doherty AS, Verona RI, Nolen LD, Schultz RM, Bartolomei MS (2004) Selective loss of imprinting in the placenta following preimplantation development in culture. Development 131:3727-3735

Marahrens Y, Panning B, Dausman J, Strauss W, Jaenisch R (1997) Xist-deficient mice are defective in dosage compensation but not spermatogenesis. Genes Dev 11:156-166

Market-Velker BA, Fernandes AD, Mann MR (2010) Side-by-side comparison of five commercial media systems in a mouse model: suboptimal in vitro culture interferes with imprint maintenance. Biol Reprod 83:938-950

Matsui J, Goto Y, Takagi N (2001) Control of Xist expression for imprinted and random $\mathrm{X}$ chromosome inactivation in mice. Hum Mol Genet 10:1393-1401

Migeon BR, Do TT (1978) In search of nonrandom X inactivation: studies of the placenta from newborns heterozygous for glucose6-phosphate dehydrogenase. Basic Life Sci 12:379-391

Migeon BR, Wolf SF, Axelman J, Kaslow DC, Schmidt M (1985) Incomplete $\mathrm{X}$ chromosome dosage compensation in chorionic villi of human placenta. Proc Natl Acad Sci USA 82:33903394

Migeon BR, Chowdhury AK, Dunston JA, McIntosh I (2001) Identification of TSIX, encoding an RNA antisense to human XIST, reveals differences from its murine counterpart: implications for $\mathrm{X}$ inactivation. Am J Hum Genet 69:951-960 
Migeon BR, Lee CH, Chowdhury AK, Carpenter H (2002) Species differences in TSIX/Tsix reveal the roles of these genes in X-chromosome inactivation. Am J Hum Genet 71:286-293

Migeon BR, Axelman J, Jeppesen P (2005) Differential X reactivation in human placental cells: implications for reversal of $\mathrm{X}$ inactivation. Am J Hum Genet 77:355-364

Mohandas TK, Passage MB, Williams JW 3rd, Sparkes RS, Yen PH, Shapiro LJ (1989) X-chromosome inactivation in cultured cells from human chorionic villi. Somat Cell Mol Genet 15:131-136

Monkhorst K, Jonkers I, Rentmeester E, Grosveld F, Gribnau J (2008) X inactivation counting and choice is a stochastic process: evidence for involvement of an X-linked activator. Cell 132:410-421

Moreira de Mello JC, de Araujo ES, Stabellini R, Fraga AM, de Souza JE, Sumita DR, Camargo AA, Pereira LV (2010) Random X inactivation and extensive mosaicism in human placenta revealed by analysis of allele-specific gene expression along the $\mathrm{X}$ chromosome. PLoS One 5:e10947

Murakami K, Araki K, Ohtsuka S, Wakayama T, Niwa H (2011) Choice of random rather than imprinted $\mathrm{X}$ inactivation in female embryonic stem cell-derived extra-embryonic cells. Development 138:197-202

Namekawa SH, Payer B, Huynh KD, Jaenisch R, Lee JT (2010) Twostep imprinted $\mathrm{X}$ inactivation: repeat versus genic silencing in the mouse. Mol Cell Biol 30:3187-3205

Navarro P, Avner P (2009) When X-inactivation meets pluripotency: an intimate rendezvous. FEBS Lett 583:1721-1727

Navarro P, Avner P (2010) An embryonic story: analysis of the gene regulative network controlling Xist expression in mouse embryonic stem cells. Bioessays 32:581-588

Navarro P, Chambers I, Karwacki-Neisius V, Chureau C, Morey C, Rougeulle C, Avner P (2008) Molecular coupling of Xist regulation and pluripotency. Science 321:1693-1695

Navarro P, Oldfield A, Legoupi J, Festuccia N, Dubois A, Attia M, Schoorlemmer J, Rougeulle C, Chambers I, Avner P (2010) Molecular coupling of Tsix regulation and pluripotency. Nature 468:457-460

Nesterova TB, Barton SC, Surani MA, Brockdorff N (2001) Loss of Xist imprinting in diploid parthenogenetic preimplantation embryos. Dev Biol 235:343-350

Nino-Soto MI, Basrur PK, King WA (2007) Impact of in vitro production techniques on the expression of $\mathrm{X}$-linked genes in bovine (bos taurus) oocytes and pre-attachment embryos. Mol Reprod Dev 74:144-153

Norris DP, Patel D, Kay GF, Penny GD, Brockdorff N, Sheardown SA, Rastan S (1994) Evidence that random and imprinted Xist expression is controlled by preemptive methylation. Cell 77:41-51

Okamoto I, Heard E (2006) The dynamics of imprinted X inactivation during preimplantation development in mice. Cytogenet Genome Res 113:318-324

Okamoto I, Otte AP, Allis CD, Reinberg D, Heard E (2004) Epigenetic dynamics of imprinted $\mathrm{X}$ inactivation during early mouse development. Science 303:644-649

Okamoto I, Arnaud D, Le Baccon P, Otte AP, Disteche CM, Avner P, Heard E (2005) Evidence for de novo imprinted X-chromosome inactivation independent of meiotic inactivation in mice. Nature 438:369-373

Okamoto I, Patrat C, Thepot D, Peynot N, Fauque P, Daniel N, Diabangouaya P, Wolf JP, Renard JP, Duranthon V, Heard E (2011) Eutherian mammals use diverse strategies to initiate X-chromosome inactivation during development. Nature 472:370-374

Owen CM, Segars JH Jr (2009) Imprinting disorders and assisted reproductive technology. Semin Reprod Med 27:417-428

Patrat C, Okamoto I, Diabangouaya P, Vialon V, Le Baccon P, Chow J, Heard E (2009) Dynamic changes in paternal X-chromosome activity during imprinted $\mathrm{X}$-chromosome inactivation in mice. Proc Natl Acad Sci USA 106:5198-5203
Peippo J, Farazmand A, Kurkilahti M, Markkula M, Basrur PK, King WA (2002) Sex-chromosome linked gene expression in in vitro produced bovine embryos. Mol Hum Reprod 8:923-929

Penny GD, Kay GF, Sheardown SA, Rastan S, Brockdorff N (1996) Requirement for Xist in $\mathrm{X}$ chromosome inactivation. Nature 379:131-137

Plath K, Mlynarczyk-Evans S, Nusinow DA, Panning B (2002) Xist RNA and the mechanism of $\mathrm{X}$ chromosome inactivation. Annu Rev Genet 36:233-278

Pugacheva EM, Tiwari VK, Abdullaev Z, Vostrov AA, Flanagan PT, Quitschke WW, Loukinov DI, Ohlsson R, Lobanenkov VV (2005) Familial cases of point mutations in the XIST promoter reveal a correlation between CTCF binding and pre-emptive choices of X chromosome inactivation. Hum Mol Genet 14:953-965

Rastan S (1982) Timing of X-chromosome inactivation in postimplantation mouse embryos. J Embryol Exp Morphol 71:11-24

Ray PF, Winston RM, Handyside AH (1997) XIST expression from the maternal $\mathrm{X}$ chromosome in human male preimplantation embryos at the blastocyst stage. Hum Mol Genet 6:1323-1327

Rivera RM, Stein P, Weaver JR, Mager J, Schultz RM, Bartolomei MS (2008) Manipulations of mouse embryos prior to implantation result in aberrant expression of imprinted genes on day 9.5 of development. Hum Mol Genet 17:1-14

Ropers HH, Wolff G, Hitzeroth HW (1978) Preferential X inactivation in human placenta membranes: is the paternal $\mathrm{X}$ inactive in early embryonic development of female mammals? Hum Genet 43:265-273

Sado T, Wang Z, Sasaki H, Li E (2001) Regulation of imprinted $\mathrm{X}$-chromosome inactivation in mice by Tsix. Development 128:1275-1286

Schoeftner S, Sengupta AK, Kubicek S, Mechtler K, Spahn L, Koseki $\mathrm{H}$, Jenuwein T, Wutz A (2006) Recruitment of PRC1 function at the initiation of $\mathrm{X}$ inactivation independent of PRC2 and silencing. EMBO J 25:3110-3122

Schultz RM (1993) Regulation of zygotic gene activation in the mouse. Bioessays 15:531-538

Shen Y, Matsuno Y, Fouse SD, Rao N, Root S, Xu R, Pellegrini M, Riggs AD, Fan G (2008) X-inactivation in female human embryonic stem cells is in a nonrandom pattern and prone to epigenetic alterations. Proc Natl Acad Sci USA 105:4709-4714

Shibata S, Yokota T, Wutz A (2008) Synergy of Eed and Tsix in the repression of Xist gene and X-chromosome inactivation. EMBO J 27:1816-1826

Shin J, Bossenz M, Chung Y, Ma H, Byron M, Taniguchi-Ishigaki N, Zhu X, Jiao B, Hall LL, Green MR, Jones SN, HermansBorgmeyer I, Lawrence JB, Bach I (2010) Maternal Rnf12/RLIM is required for imprinted $\mathrm{X}$-chromosome inactivation in mice. Nature 467:977-981

Silva J, Mak W, Zvetkova I, Appanah R, Nesterova TB, Webster Z, Peters AH, Jenuwein T, Otte AP, Brockdorff N (2003) Establishment of histone $\mathrm{h} 3$ methylation on the inactive $\mathrm{X}$ chromosome requires transient recruitment of Eed-Enx1 polycomb group complexes. Dev Cell 4:481-495

Silva SS, Rowntree RK, Mekhoubad S, Lee JT (2008) X-chromosome inactivation and epigenetic fluidity in human embryonic stem cells. Proc Natl Acad Sci USA 105:4820-4825

Silva J, Nichols J, Theunissen TW, Guo G, van Oosten AL, Barrandon O, Wray J, Yamanaka S, Chambers I, Smith A (2009) Nanog is the gateway to the pluripotent ground state. Cell 138:722-737

Starmer J, Magnuson T (2009) A new model for random X chromosome inactivation. Development 136:1-10

Sugawara O, Takagi N, Sasaki M (1985) Correlation between X-chromosome inactivation and cell differentiation in female preimplantation mouse embryos. Cytogenet Cell Genet 39:210-219

Tada T, Obata Y, Tada M, Goto Y, Nakatsuji N, Tan S, Kono T, Takagi $\mathrm{N}$ (2000) Imprint switching for non-random $\mathrm{X}$-chromosome inac- 
tivation during mouse oocyte growth. Development 127:31013105

Takagi N, Sugawara O, Sasaki M (1982) Regional and temporal changes in the pattern of X-chromosome replication during the early post-implantation development of the female mouse. Chromosoma 85:275-286

Tanasijevic B, Dai B, Ezashi T, Livingston K, Roberts RM, Rasmussen TP (2009) Progressive accumulation of epigenetic heterogeneity during human ES cell culture. Epigenetics 4:330-338

Tchieu J, Kuoy E, Chin MH, Trinh H, Patterson M, Sherman SP, Aimiuwu O, Lindgren A, Hakimian S, Zack JA, Clark AT, Pyle AD, Lowry WE, Plath K (2010) Female human iPSCs retain an inactive X chromosome. Cell Stem Cell 7:329-342

Tesar PJ, Chenoweth JG, Brook FA, Davies TJ, Evans EP, Mack DL, Gardner RL, McKay RD (2007) New cell lines from mouse epiblast share defining features with human embryonic stem cells. Nature 448:196-199

Thorvaldsen JL, Verona RI, Bartolomei MS (2006) X-tra! X-tra! News from the mouse X chromosome. Dev Biol 298:344-353

Tian D, Sun S, Lee JT (2010) The long noncoding RNA, Jpx, is a molecular switch for $\mathrm{X}$ chromosome inactivation. Cell 143:390-403

van den Berg IM, Laven JS, Stevens M, Jonkers I, Galjaard RJ, Gribnau J, van Doorninck JH (2009) X chromosome inactivation is initiated in human preimplantation embryos. Am J Hum Genet 84:771-779

Wang J, Mager J, Chen Y, Schneider E, Cross JC, Nagy A, Magnuson $\mathrm{T}$ (2001) Imprinted $\mathrm{X}$ inactivation maintained by a mouse Polycomb group gene. Nat Genet 28:371-375

Wells D, Bermudez MG, Steuerwald N, Thornhill AR, Walker DL, Malter H, Delhanty JD, Cohen J (2005) Expression of genes regulating chromosome segregation, the cell cycle and apoptosis during human preimplantation development. Hum Reprod 20:13391348

Willemsen R, Bontekoe CJ, Severijnen LA, Oostra BA (2002) Timing of the absence of FMR1 expression in full mutation chorionic villi. Hum Genet 110:601-605

Zeng SM, Yankowitz J (2003) X-inactivation patterns in human embryonic and extra-embryonic tissues. Placenta 24:270-275

Zernicka-Goetz M (2002) Patterning of the embryo: the first spatial decisions in the life of a mouse. Development 129:815-829

Zuccotti M, Monk M (1995) Methylation of the mouse Xist gene in sperm and eggs correlates with imprinted Xist expression and paternal X-inactivation. Nat Genet 9:316-320

Zuccotti M, Boiani M, Ponce R, Guizzardi S, Scandroglio R, Garagna S, Redi CA (2002) Mouse Xist expression begins at zygotic genome activation and is timed by a zygotic clock. Mol Reprod Dev 61:14-20 